\title{
Congenital Platelets Abnormality
}

National Cancer Institute

\section{Source}

National Cancer Institute. Congenital Platelets Abnormality. NCI Thesaurus. Code C61247.

A group of rare inherited platelet disorders that involve abnormalities of platelet function or platelet production and that usually cause moderate to severe bleeding problems. 